Fanum

Sociológico

\section{Forum Sociológico}

Série II

$25 \mid 2014$

Número 25

\title{
Políticas urbanas e processos de patrimonialização nas cidades de Fortaleza e de Almada
}

\section{Roselane Gomes Bezerra}

\section{(2) OpenEdition \\ 12 Journals}

Edição electrónica

URL: https://journals.openedition.org/sociologico/931

DOI: 10.4000/sociologico.931

ISSN: 2182-7427

Editora

CICS.NOVA - Centro Interdisciplinar de Ciências Sociais da Universidade Nova de Lisboa

\section{Edição impressa}

Paginação: 45-51

ISSN: 0872-8380

\section{Refêrencia eletrónica}

Roselane Gomes Bezerra, «Políticas urbanas e processos de patrimonialização nas cidades de Fortaleza e de Almada», Forum Sociológico [Online], 25 | 2014, posto online no dia 10 novembro 2014 consultado o 31 março 2022. URL: http://journals.openedition.org/sociologico/931 ; DOI: https:// doi.org/10.4000/sociologico.931

Este documento foi criado de forma automática no dia 31 março 2022.

(c) CICS.NOVA 


\title{
Políticas urbanas e processos de patrimonialização nas cidades de Fortaleza e de Almada
}

\author{
Roselane Gomes Bezerra
}

\section{Introdução}

1 Construir uma nova imagem é um desejo comum que é partilhado por muitas cidades. Esse facto justifica-se pelas transformações urbanas decorrentes da acelerada globalização económica, industrial e tecnológica que o mundo vivencia desde finais do século XX. Marcado por profundas transformações sociais, económicas e geográficas, esse século deixou como legado para a paisagem urbana a cidade pós-industrial. Nessa nova configuração a urbe surge perante os decisores políticos e urbanistas repleta de espaços em decadência ou degradação. São especialmente zonas portuárias, centros históricos e antigas instalações industriais que tiveram seus usos modificados ou tornaram-se, por diferentes motivos, ruínas com poucos vestígios do que foram.

2 O trânsito constante de pessoas e de conhecimentos, de diferentes lugares, também está a contribuir para a necessidade de definição dessa nova imagem. São cidades de diferentes países, com histórias, economias e culturas diversas, que estão a compartilhar a mesma conceção de reconstrução imagética, sobretudo por via da difusão de modelos de circulação global, que orientam práticas e políticas de intervenção, requalificação, ancorados na ideia de que preservar, remodelar ou construir são fundamentais para a patrimonialização e consequentemente para a reinvenção das cidades. Esse processo também pode ser definido como destradicionalização (Fortuna, 1997).

3 Na dinâmica de metamorfose imagética, que está a surgir como uma necessidade da urbe pós-industrial, são comuns narrativas que anunciam a valorização patrimonial como uma exigência dos projetos de requalificação. Nesse sentido, muitas vezes, os arquitetos estão a ser os únicos responsáveis por desqualificar ou atribuir o estatuto de 
património para edificações urbanas. Seja na destruição de ruínas, de edifícios envelhecidos ou na construção de novos equipamentos, os requisitos dos planos de intervenção são fundamentais para a definição dos critérios de patrimonialização.

Porém, uma questão peculiar desse processo é o caráter de dualidade que envolve a definição do património urbano. Ou seja, há uma dimensão de natureza técnica, que atende aos rigores legais e formais para a transformação de um objeto material ou imaterial em um bem com estatuto patrimonial ${ }^{1}$, e outra baseada em classificações nativas, especialmente de natureza estética, política, cultural, ou comercial. Nesse grupo, encontram-se os arquitetos que atribuem valor patrimonial para efeito de planos de requalificação. Independente de um reconhecimento oficial, estas classificações imputam a designação de património ou de valor patrimonial para objetos relacionados com o consumo visual, turístico ou de sustentação de um mercado urbano de lazeres (Leite e Peixoto, 2009).

O sentido dual do processo de patrimonialização está a ser uma característica das políticas urbanas atuais. Nesse contexto, os projetos de intervenção realçam um vínculo entre património e embelezamento arquitetónico, como uma fórmula de regeneração imagética e económica da cidade.

6 Entretanto, a ambiguidade que caracteriza esse processo fez emergir diversos questionamentos acerca dos critérios da identificação de estruturas arquitetónicas em património. A partir de uma análise das narrativas que envolvem os projetos de requalificação em duas cidades com aspetos históricos, geográficos e sociais muito diversos, como é o caso de Almada, em Portugal, e de Fortaleza, no Brasil, venho percebendo que está a existir uma disputa simbólica a respeito da autoridade dos discursos na identificação do património edificado.

7 Esse processo de patrimonialização está a conduzir a uma reflexão sobre a atribuição de valores e disputa na construção de sentidos, estabelecidos nas classificações nativas, por parte de arquitetos e também de decisores políticos e habitantes das cidades ${ }^{2}$.

O reconhecimento desse conflito gerado a partir das narrativas de arquitetos e decisores políticos, na apresentação e execução de projetos de intervenção, nas cidades de Almada e de Fortaleza, motivou as reflexões desse artigo. A observação dos discursos desses atores sociais demonstrou que, longe de existir um consenso na conceção de preservar, remodelar ou construir para patrimonializar, estas práticas, justificadas pelos planos de requalificação, estão a influenciar o surgimento de narrativas contestatárias originando um amplo debate sobre as políticas urbanas e o processo de patrimonialização nas cidades contemporâneas.

\section{Espaços urbanos como cenário ou património como alegoria}

9 Os planos de requalificação urbana estão a desempenhar um papel importante na atribuição de valores aos espaços ou edificações passíveis de tornarem-se patrimónios. São estes projetos que estão a definir o que deve ser preservado, remodelado ou construído na cidade. Porém, um outro papel importante dessas narrativas, elaboradas pelos arquitetos, é a capacidade de seduzir os decisores políticos. Estes, desejosos por um percurso que conduza à configuração de uma cidade ideal, no sentido urbanístico, estético e especialmente com soluções para as lacunas económicas que surgiram com o 
fim da cidade industrial, utilizam projetos arquitetónicos e planos urbanísticos como propaganda de políticas urbanas.

Nesse contexto, os projetos arquitetónicos estão a converter-se num elemento central para a legitimação de políticas urbanas que têm como componente principal a criação de novas centralidades e, por essa via, a mudança de imagem da cidade. Estes profissionais estão a ser os porta-estandartes dos decisores políticos e o ofício deles é assegurar a construção das narrativas adequadas para justificar o novo conceito de cidade. Como informa La Cecla (2011: 32), "o arquiteto pousa a sua capa sobre a cidade para garantir que a cidade está na moda”.

11 Nessa lógica urbana importa menos as apropriações vernáculas e mais as edificações com capacidade para atrair novos utilizadores. Para essa ideia de cidade a estética é a palavra de ordem. Contudo, o paradoxo principal desse fenómeno são os critérios, ou falta deles, na identificação de patrimónios.

12 Neil Leach refere que estamos na era da estetização. Para esse autor, nessa era, o lado menos agradável das coisas, ou, em outras palavras, da arquitetura, ganha capacidade de criar respostas aparentemente paradoxais, ao ponto de aquilo que não é, à partida, atrativo poder ser considerado esteticamente apelativo. Nesse processo, antigas instalações industriais de aspeto degradado podem tornar-se enobrecidas, velhas fábricas podem ser transformadas em apartamentos, centrais elétricas em museus nacionais, armazéns de zonas portuárias em restaurantes gourmet, ou seja, "tudo o que é repugnante e áspero parece prestar-se à estetização" (Leach, 2005: 34).

13 Nesse conceito de cidade o importante é a construção de símbolos que exaltem a urbe. Todavia, esses profissionais não são convidados pelos gestores para se dedicarem também aos impactos sociais que podem decorrer das intervenções. Nas palavras de Neil Leach (2005: 28), "a tendência para privilegiar a imagem serve para distanciar os arquitetos dos utilizadores dos respectivos edifícios, pois incentiva os primeiros a adotar uma aparência estética desfasada das preocupações dos utilizadores".

14 Os espaços cenários apresentam-se aos olhos dos decisores políticos como uma solução atrativa perante os diversos problemas que a cidade real manifesta no quotidiano. Essa conceção de espaço urbano, reproduzida nas narrativas oficiais, é legitimada pela assinatura e genialidade de um arquiteto. Como definem Leite e Peixoto (2009), nesse plano, o património funciona como alegoria, dado que o esplendor e a qualidade urbanística dos espaços em que ele se exibe ou é projetado, as cores garridas das fachadas recuperadas, equipamentos que são reformados ou construídos, contrastam com o resto da cidade que as envolve e torna-os bens investidos de um valor patrimonial. Vivemos uma espécie de museologização da vida urbana onde tradições são inventadas. "A museologização da vida urbana é um dos mais recorrentes exemplos do privilégio concedido à 'invenção' de tradições locais baseada numa aguerrida política de conservação patrimonialista do passado. (Fortuna, Barreira et al., 2013: 265).

Pensar a cidade sob o ponto de vista dos projetos de intervenção e mecanismos de patrimonialização pressupõe compreender que o lazer e o turismo estão a ser a chave para o reordenamento do território e mudança imagética da urbe. Atendendo a um apelo global de investimentos nesse setor, espaços das cidades estão a ser apropriados como um meio de gerar riquezas. Por esse motivo, os bons projetos são estabelecidos pela potencial capacidade de atração de visitantes, novos moradores ou funções económicas e comerciais. 
Encontrar novas formas de desenvolvimento económico é na verdade o ponto fulcral dessas políticas e desse processo de patrimonialização. O percurso mais comum para atingir esses objetivos está a ser visível em diferentes cidades, por meio de políticas que privilegiam o lazer e o turismo, seja através da edificação de novos centros de convenções, da reconstrução de monumentos antigos, da edificação de grandes equipamentos como aquários e centros culturais, da requalificação de centros históricos ou da transformação de espaços urbanos para grandes eventos como o campeonato mundial de futebol, jogos olímpicos ou exposições mundiais (Fortuna, 1997; Scocuglia, 2004; Ferreira, 2005; Peixoto, 2006; Barreira, 2007; Gondim, 2007; Leite, 2007; Bezerra, 2009; Rubino, 2009).

O fio condutor desse processo de políticas urbanas e patrimonialização das cidades passa por uma compreensão das narrativas dos projetos de intervenção. Esse percurso articula algumas questões referentes à atribuição de valores patrimoniais e a conflitos que se estabelecem a partir desse processo. Sem a intenção de comparar detalhadamente cidades tão distintas como Fortaleza e Almada, tomo a apresentação e execução de planos de requalificação nessas duas cidades como exemplares para a reflexão sobre as disputas que vêm sendo produzidas em torno dos processos de patrimonialização urbana.

\section{Requalificação e valores patrimoniais em Fortaleza e Almada}

Embora apresentem peculiaridades históricas muito diversas, os projetos de requalificação nas cidades de Fortaleza e de Almada assemelham-se na identificação de espaços como repositórios do passado e nos conflitos gerados a partir desse reconhecimento. No caso da cidade portuguesa, estamos diante de um típico processo de reutilização de áreas degradadas pela desindustrialização, ao passo que na cidade brasileira está em jogo a recuperação de uma área com um valor simbólico para a história da urbe. 0 ponto em comum desses processos de intervenção urbana está no facto de ambas serem áreas antigas qualificadas nas narrativas oficiais como degradadas, mas investidas de valor patrimonial graças à atribuição de um potencial turístico relacionado ao lazer e à contemplação.

$19 \mathrm{Na}$ cidade de Fortaleza, esse processo de patrimonialização tem como marco a implantação de um modelo administrativo que se iniciou nos anos 80 do século XX, e caracterizou-se por conferir prioridade às intervenções urbanísticas com finalidades de promoção do turismo e do lazer. A estratégia de valorização do passado se tornou um elemento simbólico importante para os decisores políticos, com a apresentação de narrativas que consolidaram o bairro Praia de Iracema como um lugar ideal para a implementação dessa política.

20 A Praia de Iracema foi eleita para esse processo de patrimonialização graças à sua história, especialmente devido às representações simbólicas associadas à boémia. Esta representação esteve ancorada em usos e apropriações que classificavam esse bairro como um lugar tradicional da cidade, neste sentido detentor de um património simbólico digno de atenção e vocacionado para práticas de requalificação. Segundo narrativas de arquitetos e gestores, esse bairro apresentava uma vocação natural para o lazer. Em resultado dessa política, a cidade passou a ser qualificada, em diferentes meios de 
comunicação social, como a "Miami do Nordeste" ou o "Caribe Brasileiro", facto que contribuiu para tornar Fortaleza uma das principais cidades turísticas do Brasil a partir da década de 1990 (Bezerra, 2009).

Dentre as estratégias utilizadas pelos gestores para aproveitar a vocação da Praia de Iracema, destacam-se a reconstrução do restaurante Estoril ${ }^{3}$ - ícone da boémia da cidade -, à reforma da Ponte dos Ingleses ${ }^{4}$, à construção de um calçadão na parte costeira do bairro e, sobretudo, a edificação do Centro Dragão do Mar de Arte e Cultura.

As reformas e construções que se efetivaram no bairro Praia de Iracema com o intuito de patrimonializar espaços antigos, concomitantemente às mudanças espaciais visíveis na verticalização, na instituição de áreas nobres e na preservação de zonas consideradas históricas, produziram polémicas entre habitantes e visitantes. Estes, enquanto consumidores desses espaços, passaram a ter direito a usar, modificar por meio de suas práticas sociais, reclamar e trocar, caso esses lugares não atendessem a contento as suas necessidades (Bezerra, 2009). Ou seja, ao modificarem o espaço urbano, os decisores políticos e arquitetos tornaram-se os responsáveis e é sobre eles que incidem as críticas à falta de planeamento e discordância com os novos usos e apropriações em espaços a que foi atribuído um valor patrimonial.

Nesta perspectiva, a disputa simbólica que emergiu a partir de processos de requalificação na cidade de Fortaleza caracteriza-se pela identificação de usos legítimos e não-legítimos nos espaços identificados como Património Histórico Municipal, Património Simbólico ou Cultural. Esse conflito decorre principalmente porque o critério para definição do património está associado aos usos estabelecidos historicamente. Por isso, é comum a acusação de que existem utilizadores, como prostitutas ou vendedores ambulantes, que são capazes de despatrimonializar espaços e monumentos. Ou seja, no caso de Fortaleza, especialmente na Praia de Iracema, alguns usos contribuíram para tornar a imagem do bairro como um lugar de prostitutas e gringos ou lugar do turismo sexual, práticas que foram capazes de ofuscar o valor patrimonial que antes fora conferido ao bairro.

Porém, o reconhecimento do bairro Praia de Iracema como um património da cidade e, nessa perspectiva, como representativo da memória urbana levou a um novo processo de requalificação iniciado nos anos 2010. Nesse sentido, o movimento mais recente de recuperação desse bairro abrangeu uma reforma no prédio do Estoril, a reconstrução do calçadão à beira-mar e a recuperação de algumas edificações, como a estátua de Iracema, a Ponte Metálica e o Pavilhão Atlântico. A ideia desse novo projeto é reforçar uma estratégia de valorização patrimonial da cidade voltada também para a cultura. Para esse fim está a ser projetada uma série de equipamentos, como: a Casa do Turista, a Casa da Lusofonia, o Instituto Cultural Iracema, o Museu do Olhar, o Museu do Forró e um Centro de Artesanato.

Paralelamente a estas iniciativas está a ser apresentado, pelo governo do Estado, o projeto do Acquario Ceará. A edificação desse grande equipamento está sendo muito criticada por alguns habitantes da cidade, ao ponto de ter sido organizado um movimento intitulado: Quem dera ser um peixe, que tem como objetivo questionar o investimento de um alto montante de recursos públicos para uma obra considerada não prioritária para a cidade. $\mathrm{O}$ conflito referente à apresentação desse projeto é decorrente de denúncias sobre a falta de uma discussão pública e de licitação para elaboração desse grande plano de intervenção. Há também críticas quanto à falta de um esclarecimento sobre o futuro dos habitantes do Poço da Draga - tradicional comunidade que reside, há 
mais de cem anos, próximo ao local onde será construído o Acquario - e de um debate em torno dos impactos ambientais.

Estando a Praia de Iracema identificada em diferentes discursos oficiais como o repositório do passado da cidade e como um lugar com valor patrimonial, é sobre esse bairro que vêm incidindo ao longo das duas últimas décadas a ideia de preservar, remodelar ou construir para patrimonializar. Esse processo está a ser fundamental para reforçar a imagem da cidade de Fortaleza como um lugar turístico, de lazer e cultura.

A cidade de Almada, por sua vez, está inserida, desde início dos anos 2000, em diferentes projetos de requalificação com o propósito de criar novos espaços e centralidades urbanas. Esses planos estão a contribuir para transformar a estrutura urbana da cidade e consequentemente implementar uma mudança de imagem, a qual foi durante muitos anos associada a atividades industriais (Moreira, 2004; Rodrigues, 2001). Nesse sentido, são comuns nas narrativas dos decisores políticos e arquitetos argumentos que justificam a implementação de novos espaços como uma forma de "dinamizar, reabilitar, qualificar, diversificar ou refuncionalizar a cidade".

Predomina também, nesses discursos, a argumentação de que a cidade está a ser reconstruída para o futuro valorizando ícones do passado. Nesse sentido, a freguesia de Cacilhas, uma das mais antigas da cidade, situada nas margens do rio Tejo de frente para a cidade de Lisboa, foi eleita como o lugar ideal para a implementação de muitos desses projetos que visam modificar a imagem da urbe pela via do turismo associado ao lazer e cultura ${ }^{5}$.

29 A divulgação desses planos de requalificação está fundamentada também em discursos que aliam as intervenções urbanas a uma valorização da estética da arquitetura. Porém, este modelo de planeamento que prevê uma regeneração económica, social e imagética da cidade a partir de espaços reinventados está a influenciar o surgimento de discursos e de práticas sociais contrários, ou que contestam as narrativas oficiais.

30 A estratégia da Câmara Municipal de Almada (CMA) para construir essa nova imagem e reformar algumas zonas que tiveram seus usos modificados e que se encontram degradadas centra-se na execução de projetos de intervenção que se destacam por meio da reabilitação de edifícios antigos, pedonalização de ruas, reconversão de antigos monumentos, instalação de um metro e construção de novos edifícios. É comum no discurso oficial o apelo ao desenvolvimento do turismo, lazer e cultura, a atração de jovens moradores e visitantes, a ideia de qualificação da vida das pessoas, o aproveitamento das potencialidades da cidade, o respeito pela memória e pelo património edificado, o desenvolvimento de indústrias criativas e a instalação de um Eixo das Artes.

31 Em meio a muitos projetos que estão a ser apresentados pela Câmara Municipal para diferentes áreas da cidade, a freguesia de Cacilhas se destaca pela quantidade e dimensão dos projetos, especialmente o plano de intervenção Almada Nascente-Cidade da Água, que visa construir uma nova cidade às margens do Tejo. Outros projetos importantes para essa área de Almada são: o Plano de Pormenor de Reabilitação Urbana e Funcional de Cacilhas, a Requalificação da Rua Cândido dos Reis e o Estudo de Enquadramento Estratégico da Quinta do Almaraz.

32 Segundo os decisores políticos, o objetivo do Plano de Pormenor de Cacilhas é a qualificação e patrimonialização desta área definida nos discursos oficiais como o lugar de "chegada de turistas que vêm de Lisboa". Apresentando como justificativa a excelente 
localização, os gestores estão a anunciar a criação de um espaço com "condições de desenvolvimento de recreio e de lazer", inclusive por meio do retorno de ícones do passado como o farol, que foi reimplantado, e o chafariz que foi reconstruído. Quanto à execução do projeto de Requalificação da Rua Cândido dos Reis, o objetivo foi torná-la pedonal, pois segundo um arquiteto da Câmara de Almada esta rua é "a porta de entrada da cidade". ${ }^{6}$

o Plano de Pormenor de Cacilhas está a ser apresentado como um projeto que leva em conta também a componente social. $\mathrm{O}$ arquiteto responsável por esse plano justifica essa preocupação informando que as habitações vão ser direcionadas para a população jovem e declara que "Cacilhas tem que ser o ponto de encontro de Almada, unindo turismo, habitação e comércio"7.

34 A divulgação desses planos de requalificação está fundamentada em narrativas que associam as intervenções urbanas a patrimonialização e a mudança de imagem da cidade. Porém, é exatamente este modelo de planeamento, que prevê uma regeneração económica, social e imagética a partir de espaços reinventados e da identificação de patrimónios, que está a influenciar o surgimento dos discursos que contestam as narrativas oficiais.

Esse conflito que está a existir entre as narrativas de políticos, arquitetos e habitantes emerge muitas vezes da diferença entre uma descrição prospetiva ou uma descrição etnográfica da cidade. As narrativas virtuais apresentadas nos projetos estão a seduzir os decisores políticos por meio da exaltação da estética, enquanto os habitantes contestam e apresentam outras prioridades para as políticas urbanas.

Em Almada, é comum por parte de habitantes a acusação de que existem critérios arbitrários na identificação do património, como por exemplo no caso de um moinho que será destruído independente dos apelos de alguns antigos moradores que justificam a permanência desse equipamento devido à atribuição de um valor patrimonial, sendo importante ressaltar que esse mesmo equipamento é classificado no site da freguesia de Cacilhas como património.

O processo de transformação e definição de novos espaços por meio de projetos arquitetónicos possibilita a reflexão sobre as representações do património na cidade de Almada. Para os gestores, algumas edificações do passado, que já não existem na localidade, devem retornar como um elemento de interesse patrimonial, como é o caso do chafariz, reconstruído. Nesse sentido, o património é cada vez mais apresentado como a expressão material de uma ideia pacífica de espaço público, existe uma suposta ideia de passado comum e de tradições compartilhadas (Leite e Peixoto, 2009).

Por fim é importante salientar que um outro ponto fundamental para a reflexão a respeito desse processo de transformação da cidade é a falta de estudos etnográficos nas zonas que serão requalificadas. $O$ contato direto com os diferentes praticantes permite perceber que os usos, apropriações e representações na cidade envolvem dimensões afetivas, sociais, culturais e econômicas. As situações de proximidade, proporcionadas pela etnografia, facilitam também o entendimento de como as representações de espaços degradados e de edificações com valor patrimonial são incorporadas e reproduzidas nas diversas narrativas sobre as cidades. 


\section{Considerações Finais}

39 As políticas urbanas e o processo de patrimonialização em Fortaleza e Almada demonstram diferentes formas de conflitos que se efetivam a partir da identificação de um património ou valor patrimonial em espaços urbanos. 0 intercurso possível entre essas duas cidades está na proximidade gerada pelos projetos de requalificação. Tanto na cidade de Almada como em Fortaleza, a ideia de património pressupõe um espaço público com usos harmoniosos, ou seja, a conceção de higienização dos usos na cidade está a dominar os discursos. Em ambas há uma apropriação dos planos de intervenção como o caminho para uma mudança de imagem pela via do turismo, lazer e cultura. Porém, o aspeto de distanciamento, presente na tentativa deste diálogo, incide nas diferentes atitudes dos habitantes perante o que pode ser designado como património.

o percurso de transformação imagética das cidades, aqui apresentado, é recorrente em diversos espaços urbanos e é conduzido por diferentes políticas de intervenção. Seja por meio de investimentos resultantes de grandes eventos, como foi o caso das Olimpíadas de 1994, em Barcelona, da Expo'98, em Lisboa ou através da instalação de uma grande obra arquitetónica como a construção do Museu Guggenheim em Bilbao, inaugurado em 1997, esse processo leva a patrimonialização

por meio da tríade: preservar, remodelar ou construir.

41 Nos diversos casos de intervenção urbana, esse modelo de requalificação tem em comum a conversão de espaços da cidade em áreas de interesse patrimonial, especialmente pela adoção do caráter de enobrecimento, típico deste formato, que determina que os espaços públicos devem ser ocupados por boas práticas de sociabilidade, relacionadas ao lazer, contemplação e turismo. Porém, esses processos de requalificação são capazes também de subverter os sentidos esperados pelas políticas de intervenção e deflagrar narrativas de protestos contra os projetos e os critérios de patrimonialização, como no caso de Fortaleza e de Almada.

Em Fortaleza o conflito em torno das políticas de intervenção urbana se destaca pela atribuição de usos legítimos para espaços com valor patrimonial. Desde o início do processo de requalificação nessa cidade, nomeadamente no bairro Praia de Iracema, é patente a existência de narrativas que enaltecem ou depreciam os espaços a partir de práticas sociais. Nesse sentido, percebo que nessa cidade a ideia de património está tão relacionada aos utilizadores dos espaços que usos definidos como não legítimos, para determinados habitantes, podem despatrimonializar, mesmo que de forma efémera, espaços urbanos. Por esse motivo, o processo de re-requalificação em Fortaleza pode tornar-se uma constante. Outro aspeto de disputa presente nesse processo de patrimonialização, que se aproxima da realidade da cidade de Almada, é o movimento de contestação perante práticas de intervenção apontadas pelos arquitetos como requisitos para os projetos de requalificação.

Na cidade de Almada as políticas urbanas e o processo de patrimonialização explicitam um desfasamento entre os projetos de requalificação e os praticantes da cidade (De Certeau, 1994). Tal divergência pode ser percetível por meio do conflito de narrativas entre arquitetos, decisores políticos e habitantes. Nesse contexto, os fóruns de participação, os blogues e as redes sociais tornaram-se um espaço de debate importante para a contestação desses projetos de transformação urbana. São comuns manifestações de insatisfação com os planos de requalificação em assembleias públicas, especialmente por parte de comerciantes e empresários. Assim como também são frequentes os 
protestos nos meios de comunicação virtual, especialmente em blogues, que acusam alguns projetos de destruição da cidade ou descaso com edificações com valor patrimonial.

O exame sobre as diferentes atribuições de valores e consequentes conflitos na identificação do património constitui uma questão contemporânea relativa às transformações urbanas e ao modo como se apresentam e executam projetos de requalificação nas cidades. A discordância entre espaço projetado e espaço praticado também compõe o modelo atual de urbanidade. Fortuna (2009) fala em um afastamento gradual e de não-coincidência entre o território urbanizado da cidade e o modo como se estruturam as práticas, mentalidades e relações sociais que ali se desenrolam. Para este autor, esta não-coincidência é uma demonstração da contínua reinvenção do urbano e que está a levar a um palimpsesto teórico da cidade. 0 estudo das cidades de Fortaleza e de Almada demonstra que é nessa tentativa de reinvenção que as cidades se aproximam e expõem a experiência de metamorfose imagética essencial para o contexto corrente.

\section{BIBLIOGRAFIA}

ARANTES, A. (2009), "Património cultural e cidade", in C. Fortuna e R. P. Leite (orgs.), Plural de cidade: novos léxicos urbanos, Coimbra, Almedina, pp. 11-24.

BARREIRA, I. (2007), “Usos da cidade: conflitos simbólicos em torno da memória e imagem de um bairro", in: Análise Social, vol XLII (182), Lisboa, pp. 163-179.

BEZERRA, R. G. (2009), o bairro Praia de Iracema entre o "adeus" e a "boémia": usos e abusos num espaço urbano, Fortaleza: Laboratório de Estudos da Oralidade - UFC e Expressão Gráfica.

CECLA, F. La (2011), Contra a arquitectura, Casal de Cambra, Caleidoscópio.

CERTEAU, M. De (1994), A invenção do cotidiano: artes de fazer, Petrópolis, Vozes.

FERREIRA, C. De (2005), A Expo'98 e os imaginários do Portugal contemporâneo: cultura, celebração e políticas de representação. Coimbra, tese de doutoramento, Faculdade de Economia da Universidade de Coimbra.

FORTUNA, C. (1997), "Destradicionalização e imagem da cidade: O caso de Évora”, in idem (org.), Cidade, Cultura e Globalização - Ensaios de Sociologia. Oeiras, Celta, pp. 231-257.

FORTUNA, C. (2009), “Cidade e Urbanidade”, in C. Fortuna e R. P. Leite (orgs.), Plural de Cidade: Novos Léxicos Urbanos, Coimbra, Almedina, pp. 83-97.

FORTUNA, C., I. Barreira et al. (2013), "O Passado e as Cidades: Revalorizações Patrimonialistas em Fortaleza e Coimbra”, in C. Fortuna e R. P. Leite (orgs.), Diálogos Urbanos, Coimbra, Almedina.

GONDIM, L. (2007), O Dragão do Mar e a Fortaleza Pós-Moderna: cultura, patrimônio e imagem da cidade, São Paulo, Annablume.

LEACH, N. (2005), A anestética da arquitectura, Lisboa, Antígona.

LEITE, R. P. (2007), Contra-usos da cidade: lugares e espaço público na experiência urbana contemporânea, 2.ㄹ ed., Campinas, Editora da Unicamp. 
LEITE, R. P. e P. Peixoto (2009), "Políticas urbanas de patrimonialização e contrarrevanchismo: o Recife Antigo e a Zona Histórica da Cidade do Porto”, in Cadernos Metrópole, 21, pp. 93-104.

MOREIRA, G. (2004), “Da cidade industrial à pós-industrial: Contributo para uma análise da transformação urbana em Portugal”, in Revista de Estudos Urbanos e Regionais Sociedade e Território, 37/38, pp. 27-36.

PEIXOTO, P. (2006), O passado ainda não começou: funções e estatuto dos centros históricos no contexto urbano português. Coimbra, tese de doutorado, Universidade de Coimbra.

RODRIGUES, J. S. (2001), “O Arranque da Metropolização na Margem Sul: Factores e modos de urbanização da região de Almada (1935-1947)”, in M. Pinheiro; L. V. Baptista e M. J. Vaz (orgs.), Cidade e Metrópole: Centralidades e Marginalidades, Oeiras, Celta.

RUBINO, S. (2009), “Enobrecimento urbano”, in C. Fortuna e R. P. Leite (orgs.), Plural de cidades: léxicos e culturas urbanas, Coimbra, Edições Almedina, pp. 25-40.

SCOCUGLIA, J. B. C. (2004), Revitalização urbana e (re)invenção do Centro Histórico na Cidade de João Pessoa, João Pessoa, Editora da UFPB.

\section{NOTAS}

1. Em Portugal, compete por lei ao Instituto de Gestão do Património Arquitectónico e Arqueológico/IGESPAR propor a classificação dos bens culturais imóveis de âmbito nacional. Cabe-lhe, assim, a definição dos critérios que deverão ser utilizados neste processo: critérios de carácter geral - histórico-cultural, estético-social e técnico-científico; e de carácter complementar - integridade, autenticidade e exemplaridade do bem. É assim possível encontrar hoje em dia uma maior incidência de classificações de objetos e conjuntos arquitetónicos de tipologias mais variadas, como sejam a arquitetura modernista e do movimento moderno, a arquitetura vernacular, os sítios arqueológicos, as cercas monásticas, os jardins históricos, a arquitetura do espetáculo, a arquitetura industrial, etc. $O$ ato de classificação exige uma tramitação rigorosa (recentemente alterada com a publicação do Decreto-Lei n.o 309/2009, de 23 de outubro, que entrou em vigor em janeiro de 2010). No Brasil, o património material protegido pelo Instituto do Património Histórico e Artístico Nacional/IPHAN, com base em legislações específicas, é composto por um conjunto de bens culturais classificados segundo sua natureza nos quatro Livros do Tombo: arqueológico, paisagístico e etnográfico; histórico; belas-artes; e das artes aplicadas. Eles estão divididos em bens imóveis como os núcleos urbanos, sítios arqueológicos e paisagísticos e bens individuais; e móveis como coleções arqueológicas, acervos museológicos, documentais, bibliográficos, arquivísticos, videográficos, fotográficos e cinematográficos.

2. Para Arantes (2009), a produção do património é fundamentalmente uma questão de atribuições de valores e construção de sentidos. Portanto, diferença, diversidade e conflito lhe são absolutamente inescapáveis.

3. Construído em 1925 como uma residência de veraneio, esse edifício atravessou a história do bairro em constante mutação. Durante a Segunda Guerra Mundial, foi arrendado às tropas americanas e transformado em casino, sob a denominação United States Organization. A partir de 1948 tornou-se o restaurante Estoril, que, segundo depoimentos de antigos moradores, atraía boémios e seresteiros da cidade. Com a intensificação da especulação imobiliária, no final dos anos 80, o bar e restaurante Estoril, mesmo funcionando em precárias condições físicas e de higiene, continuava a ser referenciado nos meios de comunicação como ícone da boémia da Praia de Iracema. Em 1992, o Estoril foi desapropriado pela Prefeitura Municipal e tombado como 
património cultural em 1993. Porém, em 1994 o prédio desmoronou, em decorrência de uma forte chuva. Após esse facto, largamente noticiado pela imprensa, a Prefeitura assumiu a sua imediata reconstrução (Bezerra, 2009).

4. Essa ponte teve a sua construção iniciada em 1920 por engenheiros da empresa inglesa NortonGriffiths, daí a denominação Ponte dos Ingleses. Seu objetivo era suprir as necessidades da demanda de desembarque da Ponte da Alfândega, nomeada na época como Ponte Metálica. Entretanto, como a obra ficou inacabada devido à construção do Porto do Mucuripe, esse espaço sempre foi utilizado para atividades lúdicas, como passeios e pescarias. Nos anos 1970 e 1980 a sua ocupação foi intensificada também por jovens universitários para contemplação do pôr-dosol (Bezerra, 2009).

5. A cidade de Almada tem cerca de 160.000 habitantes, pertence ao distrito de Setúbal e está dividida em 11 freguesias. Almada deixou de ser uma cidade industrial nos anos 1990, tem muitos espaços degradados, especialmente antigas instalações ligadas à indústria naval e outras indústrias nas margens do rio Tejo. É uma cidade da Grande Lisboa, mas tem um potencial turístico graças à sua proximidade a Lisboa, a algumas construções antigas e especialmente devido a uma vista espetacular para o Tejo e para a cidade de Lisboa.

6. Frases pronunciadas pelos arquitetos e decisores políticos nos Fóruns de Participação na apresentação dos projetos: Plano de Pormenor de Cacilhas e Requalificação da Rua Cândido dos Reis, em janeiro e maio de 2010.

7. Fórum de Participação: Plano de Pormenor de Cacilhas no dia 21 de janeiro de 2010.

\section{ÍNDICE}

Keywords: Heritage, regeneration, policy makers and architects

Palavras-chave: Património, requalificação, decisores políticos e arquitetos

\section{AUTOR}

\section{ROSELANE GOMES BEZERRA}

Universidade de Coimbra (lane.bezerra@hotmail.com) 